\title{
Epidemiological, Clinical and Molecular Characterization of Human Brucellosis in Bosnia and Herzegovina - An Ongoing Brucellosis Outbreak
}

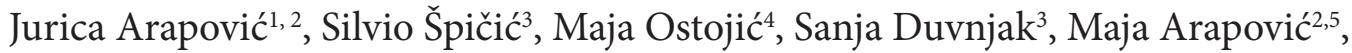 \\ Jadranka Nikolić ${ }^{1,2}, \check{Z ̌ e l j k o ~ C v e t n i c ́ ~}^{3}$
}

\begin{abstract}
${ }^{1}$ Departmet of Infectious Diseases, University Clinical Hospital Mostar, Mostar, Bosnia and Herzegovina, ${ }^{2}$ Faculty of Medicine, University of Mostar, Mostar, Bosnia and Herzegovina, ${ }^{3}$ Laboratory for Bacterial Zoonosis and Molecular Diagnostics of Bacterial Diseases of Croatian Veterinary Institute, Zagreb, Croatia, ${ }^{4}$ Institute for Microbiology and Molecular Diagnostics of University Clinical Hospital Mostar, Mostar, Bosnia and Herzegovina, ${ }^{5}$ Veterinary Institute of Herzegovina-Neretva Canton, Mostar, Bosnia and Herzegovina
\end{abstract}

$$
\begin{aligned}
& \text { Correspondence: } \\
& \text { jurica.arapovic@mef.sum.ba } \\
& \text { Tel.: + } 38736336581 \\
& \text { Fax.: + } 38736328072
\end{aligned}
$$

Received: 27 November 2017

Accepted: 11 May 2018

Key words: Bosnia and Herzegovina - Epidemic - Brucellosis - Brucella melitensis MLVA.

\section{Introduction}

Brucellosis is an emerging zoonotic infection caused by the bacterial genus Brucella. The infection is transmitted to humans from infected animals (most commonly from sheep, goats, and pigs) either by the ingestion of infected animal products, direct con-
Objective. The aim of this study was to evaluate an ongoing outbreak of brucellosis in southern region of Bosnia and Herzegovina (BIH) on the epidemiological, clinical and molecular level. Patients and methods. This study included 19 patients affected by brucellosis between 2015 and 2017, in Trebiševo (BIH). Out of 19 patients, 16 were admitted to and treated at the Department of Infectious diseases of the University Clinical Hospital Mostar, while three patients were treated in ambulatory care setting. Epidemiological, clinical and microbiological parameters were investigated. The Rose Bengal test (RBT) positive sera were serologically confirmed by complement fixation test (CFT). We also analyzed blood cultures, and isolates were additionally serotyped. Molecular analyses were performed with Bruce-ladder multiplex polymerase chain reaction (PCR) and multiple locus variable number of tandem repeat analysis of 16 loci (MLVA-16) assay. Results. Fifteen out of 19 patients had been professionally exposed to the bacterium, while four patients acquired brucellosis without prior contact with infected animals. In seven out of eight (87.5\%) patients with localized form of brucellosis, we detected significantly higher values of C-reactive protein (CRP) or erythrocyte sedimentation rate $(\mathrm{P}<0.001)$. B. melitensis was isolated from $13 / 16$ (81.3\%) blood culture samples, and additionally serotyped as biovar 3. Using MLVA16 assay, 11 isolates were genotyped. We observed complete genotype matches among 8/11 B. melitensis isolates, while 3/11 isolates differed in Bruce04 locus. Conclusion. Overall, our study confirms the usefulness of MLVA-16 method in the epidemiological and molecular research of brucellosis during epidemic that, most likely, originated from the same source. tact with an infected animal, or inhalation of infectious aerosols (1).

With more than 500,000 new cases per year (2), brucellosis continues to be the most common bacterial zoonosis worldwide and is among the major public health concerns (1). Since the actual incidence of brucello- 
sis is considered to be 26 times higher than the number of reported cases, in addition to health consequences, brucellosis represents a significant economic and financial burden to the developing endemic countries (1-4). Furthermore, four Brucella species, namely Brucella abortus, B. melitensis, B. suis and $B$. canis, are classified as category B bioterrorism agents according to the Centers for Disease Control and Prevention (CDC), as they are moderately easy to disseminate, and they result in moderate morbidity and lower mortality rates (5). Clinically, brucellosis often presents with acute symptoms such as fever, night sweats, arthralgia, myalgia, low back pain, and weight loss, as well as weakness, fatigue, malaise, headache, dizziness, depression, and anorexia. However, brucellosis may also progress to a chronic state, especially if not detected early enough due to nonspecific symptoms (1).

In Europe, brucellosis is prevalent in southern and south-eastern countries, and the highest disease incidence was reported for Greece, Former Yugoslav Republic of Macedonia, and Albania among others (2). In the Mediterranean countries and Bosnia and Herzegovina (BIH), B. melitensis is the most frequently isolated species of Brucella, which predominately affects goats and sheep (2, 6-9). In BIH, only a few isolated cases of brucellosis were reported between 1980 and $2000(6,10)$. For instance, the first case of an outbreak of human brucellosis in $\mathrm{BIH}$ was reported in 1985-1986 on the military polygon Manjača, when approximately 50 people acquired the disease after the contact with infected animals imported from the south-eastern Balkan Peninsula $(7,8,10)$. However, during the 2000s, the number of people with brucellosis rapidly increased in $\mathrm{BIH}$, peaking at $33.43 / 100,000$ citizens in 2008 (8).

After the 1992-1995 war in $\mathrm{BIH}$, the first cases of human brucellosis were reported in 1999 and 2000 following the return of refugees to the region of Trebinje (East Herzegovina, Republic of Srpska), where the source of infection was donated livestock. In the same period, another outbreak of human brucellosis occurred in Herzegovina-Neretva canton, i.e., 10 cases of human brucellosis were evidenced in Bogodol and Goranci villages (10).

Nevertheless, after the implementation of the program for mass vaccination of animals in 2009, especially of small ruminants such as sheep and goats, the incidence of human brucellosis in BIH rapidly decreased (8). One of the causes of the persistent occurrence of animal and human brucellosis in countries such as Albania, Macedonia and $\mathrm{BIH}$, is poor veterinary and health care due to a lack of systematic approach to this problem by the local politicians and professionals, during the last decade (11). Consequently, brucellosis in BIH shows a tendency to increase and become the most important public health problem in the country $(2,7$, $8,12,13$ )

Among the problems in the epidemiological research of brucellosis is the inability to perform accurate molecular subtyping of Brucella isolates, due to a high degree of similarity between the strains $(14,15)$. Tandemly repeated DNA sequences, such as minisatellites (repeat unit size $\geq 9$ base pairs) and microsatellites (repeat unit size up to 8 base pairs) have been used for the molecular distinction of different bacterial species and strains $(14,16-19)$. In this context, a technique named multiple locus variable number of tandem repeat analysis (MLVA) has proven to be useful in the genotypic distinction of Brucella strains, as well as in distinguishing new infections from relapses in patients with brucellosis $(14,15)$. The MLVA16 method met the majority of requirements for bacterial genotyping, including simplicity, typing capacity, repeatability, reproducibility, stability and epidemiological applicability $(14,16-18,20)$. 
In this study, we clinically and epidemiologically characterized an ongoing outbreak of brucellosis in the southern part of BIH with a focus on the suitability of MLVA method in molecular and epidemiological research of human brucellosis.

\section{Patients and methods}

\section{Patients}

This study included 19 patients affected by epidemic brucellosis between 2015 and 2017, in Trebiševo (BIH). Out of 19 patients, $16(84.2 \%)$ were admitted to and treated at the Department of Infectious diseases of the University Clinical Hospital Mostar, whereas the remaining three patients were treated in ambulatory care setting, without blood culture examination. We analyzed following parameters:

Socio-epidemiological characteristics e.g., gender, age, profession, way of transmission; Clinical characteristics e.g., characteristics of fever, fatigue, malaise, night sweating, loss of appetite, back pain, splenomegaly, lymphadenopathy, cough, antimicrobial consumption prior hospitalization, chronic diseases; Microbiological characteristics e.g., RBT CFT, blood cultures, genotyping; Laboratory findings e.g., C-reactive protein (CRP), erythrocyte sedimentation rate (ESR), leukocytosis, lymphocytosis $>40 \%$, Aspartate Aminotransferase (AST), Alanine Aminotransferase (ALT), Lactate dehydrogenase (LDH); Local infections (clinical manifestations or complications) of brucellosis e.g., sacroiliitis, arthritis, spondylodiscitis, endocarditis, orchitis and efficiency in the treatment.

\section{Serological analysis}

The Rose Bengal test (RBT). The RBT was used as a screening test for $B$. abortus, $B$. melitensis, and B. suis. We performed the test according to the Manual of Diagnostic Tests and Vaccines for Terrestrial Animals using Rose Bengal Brucellosis Antigen (IDEXX, Pourquier, Montpellier, France) (21).

Complement fixation test (CFT). The CFT is a serological test used to confirm the presence of complement fixating antibodies in sera of patients with brucellosis. This method was used as a confirmation test for all RBT positive sera as has been explained previously (22).

\section{Blood cultures}

We analyzed the blood cultures of 16 patients hospitalized at the Department of Infectious Diseases, University Clinical Hospital Mostar. BacT/Alert SA (aerobic) and SN (anaerobic) blood culture bottles were aseptically inoculated with $5-10 \mathrm{ml}$ of patients' blood and incubated in the BacT/Alert 3D automated sensor-metric system (bioMérieux, Marcy l'Etoile, France). The bottles were incubated under continuous agitation and monitored for five to seven days or until they became positive for bacterial growth, but no longer than 10 days.

\section{Bacterial detection and isolation}

Gram staining was performed for positive blood culture bottles. Based on the staining results, the samples positive for bacterial growth were subcultured on Brucella agar (MERCK, Darmstadt, Germany) and incubated at $37^{\circ} \mathrm{C}$, in microaerophilic conditions (10\% CO2) for at least 5 days. The suspected colonies were presumptively identified by Gram staining, as well as urease (MERCK, Darmstadt, Germany) and oxidase (bioMérieux, Marcy l'Etoile, France) tests. The Brucella isolates were characterized based on the colony morphology, positive urease and oxidase results, presence of the typical small Gram-negative coccobacilli, and molecular tests $(17,23,24)$. B. melitensis isolates were 
tested for biovars by their ability to cause agglutination of anti-A, - $\mathrm{M}$ and - $\mathrm{R}$ monospecific sera (Animal \& Plant Health Agency, formerly known as the Animal Health and Veterinary Laboratories, United Kingdom).

\section{Molecular analysis}

DNA isolation. DNA was isolated from the bacterial isolates using commercially available QIAamp DNA Mini QIAcube Kit and QIAcube system (QIAGEN, Hilden, Germany) according to the manufacturer's instructions. An amount of 2 or $5 \mu \mathrm{l}$ of the supernatant was used for further analysis.

Species identification. Bruce-ladder, a multiplex PCR assay able to differentiate between most known Brucella species, was used as a reference method for the identification of Brucella species (24). The PCR reaction mix (volume $20 \mu \mathrm{L}$ ) included: 10 $\mu \mathrm{L}$ of Multiplex PCR Master Mix (Qiagen, Hilden, Germany), $2.5 \mu \mathrm{L}$ of RNase-Free Water (Qiagen, Hilden, Germany), $0.4 \mu \mathrm{M}$ of BMEI0998f and BMEI0997r primers (Invitrogen, UK or Macrogen, Netherlands), $0.1 \mu \mathrm{M}$ of each of the remaining primers, and $2 \mu \mathrm{L}$ of DNA. The cycling protocol was used as previously described (24).

MLVA genotyping. MLVA-16 genotyping was performed with 16 gene loci as previously described $(14,17)$. The loci were classified into three panels: Panel 1 (Bruce06, 08, 11, 12, 42, 43, 45, and 55); Panel 2A (Bruce 18 and 21); and Panel 2B (Bruce04, 07, 09, 16, 30 , and Bruce19 previously included in the Panel 2A). B. melitensis $16 \mathrm{M}$ was used as the reference strain for the comparison of genotyping results and verification of test quality.

The PCR reaction mixture $(20 \mu \mathrm{L})$ was used for all MLVA loci, inlcuding: $10 \mu \mathrm{L}$ of HotStarTaq Master Mix (Qiagen, Hilden, Germany), $6 \mu \mathrm{L}$ of water (RNase-free water, Qiagen, Hilden, Germany), $0.5 \mu \mathrm{M}$ of each primer pair specific to the target locus (Invitrogen, Paisley, UK or Macrogen,
Amsterdam Zuid-Oost, Netherlands), and $2 \mu \mathrm{L}$ of template DNA. The cycling program was used as previously described (14, 17). All amplifications were performed on ProFlex PCR System (Applied Biosystems, USA). The PCR products were analyzed using QIAxcel Advanced system (QIAGEN, Hilden, Germany) with DNA size ladder in the range of 100-2500 base pairs. The DNA fragment sizes obtained with MLVA-16 assay were converted to a number of individual repeats (17). The results were presented in the form of 16-digit numerical codes based on the Brucella allele assignment table version 3.6 (25). The results of MLVA-16 were compared to the data deposited in the personal collection of strains at the Croatian Veterinary Institute.

\section{Ethics statement}

All procedures followed were in accordance with the ethical standards laid down in the 1964 Declaration of Helsinki and its later amendments. As this was a retrospective database analysis, informed consent was not required and any patient identifying information was omitted.

\section{Statistical analysis}

We analyzed the results using IBM SPSS Statistics for Windows, Version 23.0 (IBM Corp, Armonk, NY) and Microsoft Excel (365). The results are presented as absolute numbers (n) and percentages (\%). Fisher's exact test was used for categorical data analysis, due to small number of subjects, and values of $\mathrm{P}<0.05$ were considered statistically significant.

\section{Results}

Out of 19 patients with brucellosis, 11 patients (57.9\%) were females (mean age 41.9, age range $11-76)$ and 8 patients (42.1\%) were 
males (mean age 41.9, age range 8-73). Three out of 19 patients were children, whereas 16 patients were adults. The first evidenced case of this epidemic was a 13-year old girl hospitalized in the summer of 2015, while the last patient was a 62-year old woman, hospitalized in May 2016. The youngest patient was an eight-year-old boy, whereas the oldest patient was a 76-year old woman. Eleven out of 19 patients (57.9\%) had acute brucellosis, while $8 / 19$ patients $(42.1 \%)$ clinically presented with one of the following localized infections presented either by clinical manifestations or complications such as: sacroiliitis, arthritis, spondylodiscitis, endocarditis, and/or orchitis.

The majority of patients 15/19 (78.9\%) were directly involved in sheep farming (adults and farmers' children) and had a close contact with sheep during lambing. In addition, 14/19 patients (73.7\%) consumed the traditionally prepared sheep cheese and milk without prior thermal processing. Four out of $19(21 \%)$ patients did not have any prior contact with the animals.

A significant number of patients, 16/19 (84.2\%), had fever, fatigue, malaise and sweating. Splenomegaly was observed in $7 / 19$ patients $(36.8 \%)$, loss of appetite in $10 / 19$ patients $(52.6 \%)$ and back pain in $11 / 19$ patients (57.9\%). Only 3/19 patients (15.8\%) did not have any clinical symptoms of brucellosis.

Increased levels of erythrocyte sedimentation rate (ESR) and C-reactive protein (CRP) were observed in 12/19 (63.2\%) and $11 / 17(64.7 \%)$ examined patients, respectively. Elevated levels of leukocytes were observed only in two out of 19 patients (10.5\%), while in $11 / 19$ patients $(57.9 \%)$ relative lymphocytosis was present. Increased lactate dehydrogenase (LDH) was observed in $14 / 19(73.8 \%)$ patients and elevated hepatic transaminases were detected in $8 / 19$ (42.1\%) patients (Table 1 ).
Table 1. Socio-epidemiological, clinical and microbiological characteristics of patients with brucellosis

\begin{tabular}{|c|c|c|}
\hline Characteristics & $\mathrm{n} /$ total & (\%) \\
\hline \multicolumn{3}{|l|}{ Gender } \\
\hline Male & $8 / 19$ & $(42.1)$ \\
\hline Female & $11 / 19$ & (57.9) \\
\hline \multicolumn{3}{|l|}{ Age } \\
\hline Children (8-17 years) & $3 / 19$ & $(15.8)$ \\
\hline Adults (>18 years) & $16 / 19$ & $(84.2)$ \\
\hline \multicolumn{3}{|l|}{ Age range (year) } \\
\hline $8-17$ & $3 / 19$ & $(15.8)$ \\
\hline $18-44$ & $6 / 19$ & (31.6) \\
\hline $45-64$ & $5 / 19$ & (26.3) \\
\hline$>65$ & $5 / 19$ & (26.3) \\
\hline \multicolumn{3}{|l|}{ Profession } \\
\hline Pupils (farmers' children) & $3 / 19$ & $(15.8)$ \\
\hline Farmers & $12 / 19$ & $(63.2)$ \\
\hline Tourists & $4 / 19$ & (21.0) \\
\hline \multicolumn{3}{|l|}{ Possible transmission } \\
\hline Aerosol & $3 / 19$ & (15.8) \\
\hline Ingestion & $14 / 19$ & (73.7) \\
\hline Contact & $15 / 19$ & (78.9) \\
\hline No prior contact & $4 / 19$ & (21.0) \\
\hline \multicolumn{3}{|l|}{ Fever } \\
\hline No fever & $3 / 19$ & $(15.8)$ \\
\hline Fever $<15$ days & 9/19 & (47.4) \\
\hline Fever $>15$ days & $7 / 19$ & (36.8) \\
\hline \multicolumn{3}{|l|}{ Symptoms } \\
\hline Fatigue & $16 / 19$ & $(84.2)$ \\
\hline Malaise & $16 / 19$ & $(84.2)$ \\
\hline Sweating & $16 / 19$ & $(84.2)$ \\
\hline Loss of appetite & $10 / 19$ & (52.6) \\
\hline Back pain & $11 / 19$ & (57.9) \\
\hline Splenomegaly & $7 / 19$ & (36.8) \\
\hline Lymphadenopathy & $2 / 19$ & $(10.5)$ \\
\hline Cough & $1 / 19$ & $(5.3)$ \\
\hline Antimicrobials prior hospitalization & $3 / 19$ & $(15.8)$ \\
\hline Presence of other chronic disease & $5 / 19$ & (26.3) \\
\hline \multicolumn{3}{|l|}{ Microbiological characteristics } \\
\hline RBT (Rose Bengal test) & $19 / 19$ & $(100)$ \\
\hline Complement fixation test (CFT) & $18 / 19$ & (94.7) \\
\hline Blood culture positive & $13 / 16$ & (81.3) \\
\hline Genotyping - performed & $11 / 13$ & (84.6) \\
\hline
\end{tabular}


Table 1 (continued): Socio-epidemiological, clinical and microbiological characteristics of patients with brucellosis

\begin{tabular}{lrl}
\hline Characteristics & $\mathrm{n} /$ total & $(\%)$ \\
\hline Genotyping - not performed & $2 / 13$ & $(15.4)$ \\
\hline Laboratory findings & & \\
\hline CRP not performed & $2 / 19$ & $(10.5)$ \\
\hline CRP $<5 \mathrm{mg} / \mathrm{mL}$ & $6 / 19$ & $(31.6)$ \\
\hline CRP $5-49 \mathrm{mg} / \mathrm{mL}$ & $7 / 19$ & $(36.8)$ \\
\hline CRP $50-99 \mathrm{mg} / \mathrm{mL}$ & $2 / 19$ & $(10.5)$ \\
\hline CRP $>100 \mathrm{mg} / \mathrm{mL}$ & $2 / 19$ & $(10.5)$ \\
\hline ESR $<25 \mathrm{~mm} / \mathrm{h}$ & $12 / 19$ & $(63.2)$ \\
\hline ESR $>25 \mathrm{~mm} / \mathrm{h}$ & $7 / 19$ & $(36.8)$ \\
\hline Leukocytosis & $2 / 19$ & $(10.5)$ \\
\hline Lymphocytosis $>40 \%$ & $11 / 19$ & $(57.9)$ \\
\hline AST $>30 \mathrm{mU} / \mathrm{mL}$ & $8 / 19$ & $(42.1)$ \\
\hline ALT $>35 \mathrm{mU} / \mathrm{mL}$ & $8 / 19$ & $(42.1)$ \\
\hline LDH $>225 \mathrm{mU} / \mathrm{mL}$ & $14 / 19$ & $(73.7)$ \\
\hline Clinical manifestations or complications & & \\
\hline No & $11 / 19$ & $(57.9)$ \\
\hline Sacroiliitis & $2 / 19$ & $(10.5)$ \\
\hline Arthritis & $1 / 19$ & $(5.3)$ \\
\hline Spondylodiscitis & $3 / 19$ & $(15.8)$ \\
\hline Spondylodiscitis and endocarditis & $1 / 19$ & $(5.3)$ \\
\hline Orchitis & $1 / 19$ & $(5.3)$ \\
\hline Efficiency in treatment & & \\
\hline Mortality & $1 / 19$ & $(5.3)$ \\
\hline Successfully treated & $0 / 19$ & $(94.7)$ \\
\hline Relapses (one year follow up) & $(0.0)$ \\
\hline CRP & & \\
\hline
\end{tabular}

$\mathrm{CRP}=\mathrm{C}$-reactive protein; $\mathrm{ESR}=$ Erythrocyte sedimentation rate; AST=Aspartate aminotransferase; ALT=Alanine aminotransferase; $\mathrm{LDH}=$ Lactate dehydrogenase.
The blood cultures were microbiologically positive for bacterial growth in $13 / 16$ $(81.3 \%)$ patients and further analyzed with Bruce-Ladder PCR method for the final confirmation of Brucella species. The assay showed the presence of B. melitensis in all blood culture isolates. According to positive agglutination with anti-A and anti $-\mathrm{M}$ monospecific sera all isolated strains were typed as B. melitensis biovar 3 .

In addition, we investigated the relationship between acute inflammatory markers (e.g., CRP and ESR) and the severity of the disease. The levels of CRP above $20 \mathrm{mg} / \mathrm{L}$ were observed in $7 / 17$ (41.2\%) patients presented with localized form of brucellosis, while only in one out of eight patients with localized form of brucellosis lower CRP was observed $(\mathrm{P}<0.001)$. Similarly, in $7 / 19$ $(36.8 \%)$ patients with localized form of brucellosis ESR above $25 \mathrm{~mm} / \mathrm{h}$ was observed $(\mathrm{P}<0.001)$. On the other hand, in patients without localized form of brucellosis, CRP below $20 \mathrm{mg} / \mathrm{L}$ (in 9/17 patients; 52.9\%) and normal ESR (in 11/19 patients; $57.9 \%$ ) were observed $(\mathrm{P}<0.001)$ (Table 2).

Finally, we performed a molecular characterization in 11/13 human blood isolates using MLVA-16. As shown in Figure 1, B. melitensis was detected in all 11 isolates, indicating that these 11 patients were part of the same brucellosis epidemic. The Bruce04 and Bruce 16 from the panel $2 \mathrm{~B}$ were the only polymorphic loci.

Table 2. Relationship between markers of acute inflammation and severity of brucellosis

\begin{tabular}{llll}
\hline \multirow{2}{*}{$\begin{array}{l}\text { Inflammatory } \\
\text { markers }\end{array}$} & Localized infection & \multicolumn{2}{l}{$\mathrm{P}^{*}$} \\
\cline { 2 - 4 } & Presence $(\mathrm{n} ; \%)$ & Absence $(\mathrm{n} ; \%)$ & $<0.001$ \\
\hline $\mathrm{CRP}>20 \mathrm{mg} / \mathrm{L}$ & $7 / 17(41.2)$ & $0(0 \%)$ & $<0.001$ \\
\hline $\mathrm{CRP}<20 \mathrm{mg} / \mathrm{L}$ & $1 / 17(5.9)$ & $9 / 17(57.9)$ & - \\
\hline Total & $8 / 17(47.1)$ & $9 / 17(52.9)$ & $<0.001$ \\
\hline ESR $>25 \mathrm{~mm} / \mathrm{h}$ & $7 / 19(36.8)$ & $0 / 19(0 \%)$ & $<0.001$ \\
ESR $<25 \mathrm{~mm} / \mathrm{h}$ & $1 / 19(5.3)$ & $11 / 19(57.9)$ & - \\
\hline Total & $8 / 19(42.1)$ & $11 / 19(57.9)$ & \\
\hline
\end{tabular}

*Fisher's exact test; $C R P=C$-reactive protein; $E S R=$ Erythrocyte sedimentation rate. **In two patients without localized form of brucellosis CRP was not performed. 


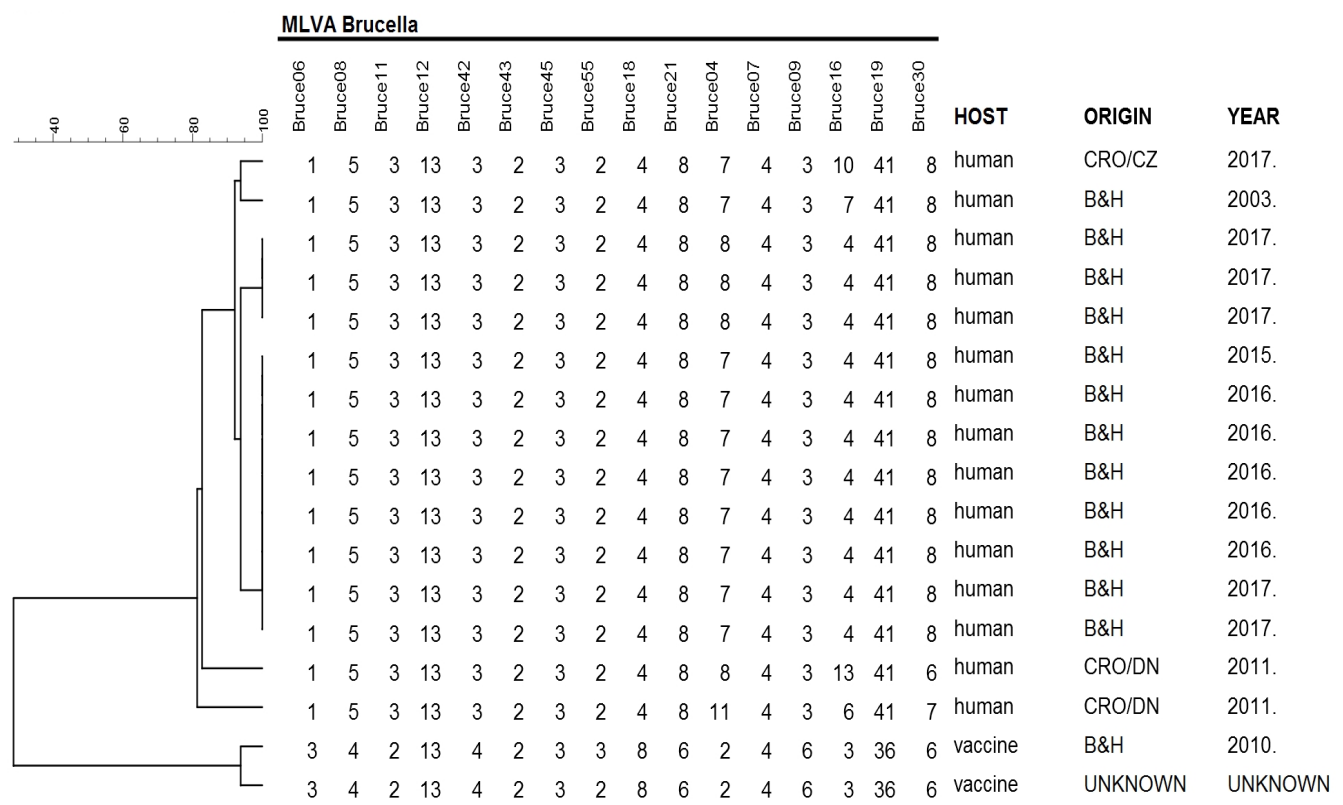

Figure 1. Dendrogram obtained with the results of multi-locus variable-number tandem repeat analysis-16 (MLVA-16) genotyping assay showing the relationships between 11 Brucella isolates obtained from patients from Trebiševo (BIH) in the period 2015-2017 and additional five marked strains collected from three individuals from Croatia (Canton Zagreb, CZ; Canton Dubrovnik-Neretva, DN) and one from BIH isolated previously, as well as two $B$. melitensis Rev. 1 vaccine strains. The individual MLVA-16 loci and the number of variable number tandem repeats for each isolate are shown.

During this epidemic, a 65-year old man died from severe complications of brucellosis, i.e., spondylodiscitis and endocarditis resulting in embolization of central nervous system. Eighteen patients (94.7\%) were successfully treated without any relapse of the disease in one year follow up.

\section{Discussion}

An important point of our study is that this epidemic was related to the specific method of sheep milk collection, followed by the traditional way of preparing sheep cheese in Herzegovina, which does not require prior thermic processing. Another crucial point is that a large number of sheep from different households (more than 15 different farms) were pooled to make a larger livestock group (around 800 animals) on a mountain ranch, where more vegetation is present during the summer time.
This epidemic of brucellosis started in 2015, when we detected two patients who were in direct contact with sheep and had been preparing different sorts of milk products, but without any serious epidemiological and sanitary inspection. Next year, in the autumn of 2016, we registered the second outbreak of human brucellosis when additional 10 patients were hospitalized. Importantly, this epidemic occurred in the same location as in 2015. Since this time more people were affected, a serious veterinary and epidemiological investigation was conducted. Because most of the sheep had not been vaccinated, brucellosis quickly spread among the animals. Moreover, because the vaccination program has not been consistently carried out in BIH (11), during the past years, a significant number of new animals had been acquiring brucellosis and consequently pose a threat to humans. During this epidemic, brucellosis was con- 
firmed in 81 out of 800 tested sheep. The infected animals were properly euthanized and disposed outside the inhabited area in Trebiševo, while the rest of the seronegative herd was returned to farms throughout Herzegovina in the late autumn of 2016 (data not shown). Three patients, who had been in a close contact with infected sheep within the farm household, were serologically positive for RBT, whereas most of other family members, who had not had contact with the animals, were negative. In accordance with previous recommendations (26), the seronegative people who had been exposed to the infected animals were continuously tested in the following period, and ten of them were serologically positive for brucellosis, even six months after their last contact with infected sheep. The last outbreak of the disease occurred in the spring of 2017, when we hospitalized and treated seven additional patients with brucellosis. Furthermore, the seronegative sheep were re-tested and most of them were serologically positive for brucellosis, including five cattle in one of the two tested farm households (data not shown). This confirms that $B$. melitensis is highly pathogenic and can cross the species barrier between different mammals (1).

Although brucellosis is a professional disease $(6-9,12,27-30)$, here we reported that four out of 19 infected patients had no previous contact with any type of livestock. However, they visited Trebiševo or ate the traditionally prepared cheese in 2016, and most probably acquired the disease either by aerosol or ingestion of the infected food, which has also been reported previously (1, 31-33). Moreover, as ocular infection was suggested by some authors, especially in laboratory conditions, we assumed that some of the patients could have been infected through the conjunctiva (1).

The RBT is still considered to be the best screening tool for brucellosis (34). Three of our patients had no symptoms of brucello- sis, and among these, one patient had negative complement fixation test (CFT). On the other hand, RBT was positive in all three patients. This result is in correlation with previously published reports showing a high level of sensitivity for RBT, even as compared with a more specific serological test such as CFT or serum agglutination test (SAT) (34, 35). In the patient with the RBT positive and CFT negative result, Brucella was isolated from the blood culture, indicating septicemia. Finally, all isolated strains were typed to belong to $B$. melitensis biovar 3 which is to our knowledge first systematic report of human B. melitensis isolates in $\mathrm{BIH}$.

Microbiological isolation remains the "gold standard" for the diagnosis of brucellosis and the sensitivity of this method varies from 15 to $70 \%$ (1). Compared to the efficacy of the blood isolation methods in other medical centers in $\mathrm{BIH}$ (36), the sensitivity of our method was higher as more than $80 \%$ of blood cultures were positive. The high rate of positive blood cultures was the result of our careful planning during the sampling of patients highly susceptible for brucellosis.

In contrast to previously published results, where the majority of patients with brucellosis from BIH were males $(6,8)$, in our group, brucellosis was equally distributed among the males and females. Moreover, almost a half of our patients had a clinical manifestations of brucellosis, indicating that either the acute disease was not recognized by the primary health service or the patients did not have symptomatic acute disease. Also, there is a possibility that some of patients did not want to visit the primary health service. This suggests that, in the case of epidemic history in the specific region, the primary health care service should be more aware of the infection.

Patients with brucellosis often have elevated ESR and CRP levels (37). In this study, we observed that the elevated ESR and CRP levels were strongly associated with differ- 
ent disease presentations. For example, the acute inflammatory markers were markedly higher in our patients with localized form of brucellosis, indicating their role in diagnostics and therapy planning for the patients.

In our study, all patients were treated for at least eight weeks, with minimum two, combined antimicrobial agents. The adults and children $>8$ years old were treated with a combination of doxycycline $100 \mathrm{mg}$ p.o. twice a day (BID) and gentamicin $(5 \mathrm{mg} / \mathrm{kg})$ once a day for two to three weeks, followed by a combination of doxycycline $100 \mathrm{mg}$ p.o. BID and rifampicin $300 \mathrm{mg}$ p.o. BID for at least five additional weeks, but more often up to 12 weeks, especially when septicemia was detected. In the case of focal disease, such as spondylodiscitis, longer therapy may be more beneficial (38). The described therapy resulted in complete remission of brucellosis, with no relapse history.

Finally, we performed the genotype analysis of the Brucella isolates and correlated these results to the region of origin of this ongoing brucellosis outbreak in BIH. Similar to a previous report (39), using molecular (MVLA) and serological techniques (antisera M, A and R) we also showed that B. melitensis biovar 3 was the predominant strain in BIH. In most of our Brucella isolates similar genotypes were present, and only in three patients, all from the same family, small sequence differences were observed for the Bruce04 locus. A high mutation rate for the Bruce 04 and Bruce 16 loci was also recently reported by Kattar et al. in $42 \mathrm{~B}$. melitensis strains isolated from patients from Lebanon (15), as well as by Cvetnic et. al. in 29 B. melitensis animal isolates originating from Croatia and BIH (40). Similarly, the $B$. melitensis isolates reported in this study and in the previous studies from $\mathrm{BIH}$ and the neighboring countries mostly differed in the locus Bruce16. All these results suggest that the locus Brucel6 is among the most variable loci in the analyzed panels, indicating its importance in the epidemiological and molecular research of B. melitensis. Recently, Gyuranecz et al. demonstrated rapid in vivo genetic mutations of several variable number tandem repeats loci in $B$. canis isolates from dogs, over a three-month period of outbreak (41), which also could indicate the possibility of minor mutations in some of the variable loci of $B$. melitensis during epidemic.

\section{Conclusion}

Overall, our study confirms the usefulness of MLVA-16 method in the epidemiological and molecular research of brucellosis in $\mathrm{BIH}$ and neighboring countries. In addition, the genotypes of Brucella strains isolated from 2003 up until now from the samples in BIH show high similarity and indicate the presence of a regional epidemic. Future research should analyze this phenomenon in detail, by investigating all cases of the local outbreaks of brucellosis in $\mathrm{BIH}$.

\section{What is already known on this topic}

Brucellosis is an endemic disease in BIH for more than 15 years representing an emergent treat for people in the country and region. Clinical and epidemiological characteristics of brucellosis are well known. So far, in BIH only B. melitensis was isolated from humans with brucellosis, but there are no molecular data about circulating genotypes.

\section{What this study adds}

To date, there were no studies investigating correlation between molecular and epidemiological characteristics of Brucella spp. in the region. We clinically and epidemiologically investigated an ongoing outbreak of brucellosis in the southern part of BIH with a focus on the suitability of Brucella spp. genotyping by MLVA-method in epidemiological research of human brucellosis. In this study B. melitensis biovar 3 was detected in all investigated isolates. Furthermore, the Bruce 04 and Bruce 16 were the most polymorphic loci. Although complete genotype matches were detected in the majority of $B$. melitensis isolates, only few isolates slightly differed in Bruce04 locus suggesting that the strains in this region, most likely, originated from the same source.

Aknowlegments: We thank Dr. Miroslav Benić for constructive discussion regarding the statistical analysis. 
Authors' contributions: Conception and design: JA, SŠ, MA, JN and ŽC; Acquisition, analysis and interpretation of data: JA, Š́, MO, SD, MA, JN and ŽC; Drafting the article: JA and SŠ; Revising it critically for important intellectual content: JA, SŠ and MA; Approved final version of the manuscript: JA, SŠ, MO, $\mathrm{SD}, \mathrm{MA}$, JN and ŽC.

Conflict of interest: The authors declare that they have no conflict of interest.

\section{References}

1. Pappas G, Akritidis N, Bosilkovski M, Tsianos E. Brucellosis. N Engl J Med. 2005;352(22):2325-36.

2. Pappas G, Papadimitriou P, Akritidis N, Christou L, Tsianos EV. The new global map of human brucellosis. Lancet Infect Dis. 2006;6(2):91-9.

3. Stoenner HG, Jenkins AA, Bramhall EH. Studies of brucellosis in Utah. J Infect Dis. 1949;85(3):21324.

4. Wise RI. Brucellosis in the United States. Past, present, and future. JAMA. 1980;244(20):2318-22.

5. Centers for Disease C, Prevention. Suspected brucellosis case prompts investigation of possible bioterrorism-related activity--New Hampshire and Massachusetts, 1999. MMWR Morb Mortal Wkly Rep. 2000;49(23):509-12.

6. Ahmetagic S, Tihic N, Ahmetagic A, Custovic A, Smriko-Nuhanovic A, Mehinovic N, et al. Human brucellosis in Tuzla Canton. Med Arch. 2012;66(5):309-14.

7. Krkic-Dautovic S, Mehanic S, Ferhatovic M, Cavaljuga S. Brucellosis epidemiological and clinical aspects (Is brucellosis a major public health problem in Bosnia and Herzegovina?). Bosn J Basic Med Sci. 2006;6(2):11-5.

8. Obradovic Z, Velic R. Epidemiological characteristics of brucellosis in Federation of Bosnia and Herzegovina. Croat Med J. 2010;51(4):345-50.

9. Punda-Polic V, Cvetnic Z. Human brucellosis in Croatia. Lancet Infect Dis. 2006;6(9):540-1.

10. Ahmetagić S, Piljić D, Smirko-Nuhanović A, Ahmetagić A, B. T. Clinical and Epidemiological Characteristics of Brucellosis in Hospitalised Patients. Croatian Journal of Infection. 2008;28(3):135-43.

11. Moreno E. Retrospective and prospective perspectives on zoonotic brucellosis. Front Microbiol. 2014;5:213.

12. Taleski V, Zerva L, Kantardjiev T, Cvetnic Z, Erski-Biljic M, Nikolovski B, et al. An overview of the epidemiology and epizootology of brucellosis in selected countries of Central and Southeast Europe. Vet Microbiol. 2002;90(1-4):147-55.

13. Hukic M, Numanovic F, Sisirak M, Moro A, Dervovic E, Jakovec S, et al. Surveillance of wildlife zoonotic diseases in the Balkans Region. Med Glas (Zenica). 2010;7(2):96-105.

14. Al Dahouk S, Fleche PL, Nockler K, Jacques I, Grayon M, Scholz HC, et al. Evaluation of Brucella MLVA typing for human brucellosis. J Microbiol Methods. 2007;69(1):137-45.

15. Kattar MM, Jaafar RF, Araj GF, Le Fleche P, Matar GM, Abi Rached R, et al. Evaluation of a multilocus variable-number tandem-repeat analysis scheme for typing human Brucella isolates in a region of brucellosis endemicity. J Clin Microbiol. 2008;46(12):3935-40.

16. Bricker BJ, Ewalt DR, Halling SM. Brucella 'HOOF-Prints': strain typing by multi-locus analysis of variable number tandem repeats (VNTRs). BMC Microbiol. 2003;3:15.

17. Le Fleche P, Jacques I, Grayon M, Al Dahouk S, Bouchon P, Denoeud F, et al. Evaluation and selection of tandem repeat loci for a Brucella MLVA typing assay. BMC Microbiol. 2006;6:9.

18. Whatmore AM, Perrett LL, MacMillan AP. Characterisation of the genetic diversity of Brucella by multilocus sequencing. BMC Microbiol. 2007;7:34.

19. Whatmore AM, Shankster SJ, Perrett LL, Murphy TJ, Brew SD, Thirlwall RE, et al. Identification and characterization of variable-number tandemrepeat markers for typing of Brucella spp. J Clin Microbiol. 2006;44(6):1982-93.

20. Bricker BJ, Ewalt DR. Evaluation of the HOOFPrint assay for typing Brucella abortus strains isolated from cattle in the United States: results with four performance criteria. BMC Microbiol. 2005;5:37.

21. Brucellosis (Brucella abortus, B. melitensis and B. suis) (infection with B. abortus, B. melitensis and B. suis ). In: Manual of diagnostic tests and vaccines for terrestrial animals. Paris: Office international des epizooties. 2008:1-44.

22. Spicic S, Zdelar-Tuk M, Racic I, Duvnjak S, Cvetnic Z. Serological, bacteriological, and molecular diagnosis of brucellosis in domestic animals in Croatia. Croat Med J. 2010;51(4):320-6.

23. Alton GG, Jones LM, Pietz DE. Laboratory techniques in brucellosis. Monogr Ser World Health Organ. 1975(55):1-163.

24. Lopez-Goni I, Garcia-Yoldi D, Marin CM, de Miguel MJ, Munoz PM, Blasco JM, et al. Evaluation of a multiplex PCR assay (Bruce-ladder) for molecular typing of all Brucella species, in- 
cluding the vaccine strains. J Clin Microbiol. 2008;46(10):3484-7.

25. Grissa I, Bouchon P, Pourcel C, Vergnaud G. Online resources for bacterial micro-evolution studies using MLVA or CRISPR typing. Biochimie. 2008;90(4):660-8.

26. Tabak F, Hakko E, Mete B, Ozaras R, Mert A, Ozturk R. Is family screening necessary in brucellosis? Infection. 2008;36(6):575-7.

27. Ali S, Ali Q, Neubauer H, Melzer F, Elschner M, Khan I, et al. Seroprevalence and risk factors associated with brucellosis as a professional hazard in Pakistan. Foodborne Pathog Dis. 2013;10(6):5005.

28. Shome R, Kalleshamurthy T, Shankaranarayana PB, Giribattanvar P, Chandrashekar N, Mohandoss N, et al. Prevalence and risk factors of brucellosis among veterinary health care professionals. Pathog Glob Health. 2017;111(5):234-9.

29. Tandir S, Sivic S, Toromanovic S, Alicajic F. Epidemiology features of brucellosis at the ZenicaDoboj Canton area in period 2000-2007. Med Arh. 2008;62(2):111-3.

30. Zvizdic S, Cengic D, Bratic M, Mehanic S, Pinjo F, Hamzic S. Brucella melitensis: review of the human infection case. Bosn J Basic Med Sci. 2006;6(1):15-8.

31. Arnow PM, Smaron M, Ormiste V. Brucellosis in a group of travelers to Spain. JAMA. 1984;251(4):505-7.

32. Dhanashekar R, Akkinepalli S, Nellutla A. Milkborne infections. An analysis of their potential effect on the milk industry. Germs. 2012;2(3):101-9.

33. Humphrey TJ. Food- and milk-borne zoonotic infections. J Med Microbiol. 1997;46(1):11-3, 28-33.
34. Diaz R, Casanova A, Ariza J, Moriyon I. The Rose Bengal Test in human brucellosis: a neglected test for the diagnosis of a neglected disease. PLoS Negl Trop Dis. 2011;5(4):e950.

35. Mert A, Ozaras R, Tabak F, Bilir M, Yilmaz M, Kurt C, et al. The sensitivity and specificity of Brucella agglutination tests. Diagn Microbiol Infect Dis. 2003;46(4):241-3.

36. Sisirak M, Hukic M. Evaluation and importance of selected microbiological methods in the diagnosis of human brucellosis. Bosn J Basic Med Sci. 2009;9(3):198-203.

37. Buzgan T, Karahocagil MK, Irmak H, Baran AI, Karsen H, Evirgen O, et al. Clinical manifestations and complications in 1028 cases of brucellosis: a retrospective evaluation and review of the literature. Int J Infect Dis. 2010;14(6):e469-78.

38. Arapović J, Skočibušić S, Soldo I, Arapović M, Cvetnić Ž, Nikolić J. Conservative treatment of lumbar brucellar spondylodiscitis with epidural abscess - A case report. Croatian Journal of Infection. 2016; 36:2(2):81-5.

39. Tappe D, Melzer F, Schmoock G, Elschner M, Lam TT, Abele-Horn M, et al. Isolation of Brucella melitensis biotype 3 from epidural empyema in a Bosnian immigrant in Germany. J Med Microbiol. 2012;61(Pt 9):1335-7.

40. Cvetnić Ž, Zdelar-Tuk M, Duvnjak S, Račić M, Škrivanko M, Špičić S. Multiple locus variable number of tandem repeat analysis (MLVA) of isolates of Brucella melitensis isolated in the Republic of Croatia. Vet arhiv. 2015;85:481-92.

41. Gyuranecz M, Rannals BD, Allen CA, Janosi S, Keim PS, Foster JT. Within-host evolution of Brucella canis during a canine brucellosis outbreak in a kennel. BMC Vet Res. 2013;9:76. 